\title{
LOC-LEACH: An Enhanced LEACH protocol for WSNs
}

\author{
Mohammed Réda El Ouadi ${ }^{1}$, Abderrahim Hasbi ${ }^{2}$ \\ ${ }^{1}$ Mohammadia School of Engineers, Mohammed V University, Rabat, Morocco, elouadi.mr@gmail.com \\ ${ }^{2}$ Mohammadia School of Engineers, Mohammed V University, Rabat, Morocco, hasbi@emi.ac.ma
}

\begin{abstract}
Wireless sensor networks represent a set of sensor nodes distributed in area we are concerned, in order to monitor a specific environment and transmit the obtained data to base station. Each sensor node is characterized by limited capacities in terms of computing, processing, communication and energy capacity. Due to the difficulty of recharging or replacing their batteries, several researches are interested in minimizing the energy consumption to prolong the wireless sensor networks lifetime. In this work, we propose a new concept to improve low-energy adaptive clustering hierarchy(LEACH) protocol, named LocationBased LEACH (LOC-LEACH). The improved method is based to introduce two techniques. First, we distribute all sensor nodes of network in 3 logical regions according to their location information, and we propose a new concept for optimizing cluster head selection. Simulations results show that the proposed LOC-LEACH protocol provides more energy-efficient in terms of stability and network lifetime than LEACH protocol. Additionally, the protocol can considerably decrease an unnecessary waste of energy caused by cluster formation process proposed by LEACH protocol.
\end{abstract}

Key words : WSNs, Routing protocols, Energy consumption, Location-based, LEACH, Network lifetime

\section{INTRODUCTION}

The Wireless sensor networks (WSNs) consist to group many sensors to observe a particular environment with a specific objective defined [1], [2]. Sensor nodes can be deployed in different environments to collect information, such as environment phenomena like temperature and humidity, road traffic, healthcare services and military operation[3]. These nodes communicate each other and report the information to the base station (BS)[4], responsible to collect data from all nodes at the region of interest. The crucial point is almost impossible to change the battery of each node, particularly in inaccessible environments [5]. Due to their limited energy, the energy efficiency is considered as a big challenge to resolve WSN lifetime constraint [2],[6]. Thus, WSN has become a rich field for researchers, aim to propose the best method to use efficiently the energy of sensor nodes. Wireless sensor networks consume a substantial amount of their energy to organize sensor nodes and achieve routing tasks [2], [7]. Routing protocols in WSNs are responsible for discovering and maintaining the best routes in transmission phase between nodes, hence the importance role of routing protocols in energy consumption and network lifetime[8].

Routing protocols in WSNs can be divided according to several methods. According to network structure, they can be classified in 3 types: Location-based, Flat and Hierarchical protocols. In location-based protocols, the aim objective is to select the best path to allow a minimum energy consumption [9]. However, the Flat-based routing uses a multi-hop technique for transmitting data between nodes, and they perform the same roles and collaborate of theme to make the sensing task) [4]. Among all these types of protocols, hierarchical cluster based protocol is the popular and efficient mechanism to reach these objectives [2]. The hierarchical routing protocols consist to group nodes into clusters, respecting to specific metrics. The clusters are formed of many ordinary nodes and one leader node named cluster head $(\mathrm{CH})$. The $\mathrm{CH}$ is considered the most crucial component to manage in the hierarchical routing protocol [10], [11]. LEACH is one of the most popular protocols which has proposed this technique[10], and has been improved by various researchers in order to solve the energy efficient and increase the WSN performance, such as Centralized LEACH (LEACH-C) in which node location information and energy, are used by the base station to organize the clusters. Two-level LEACH (TL-LEACH) presents a new concept by organizing the $\mathrm{CH}$ in two levels to transmit data to the BS. Bani Yassein et al present Vice-Leach protocol (V-LEACH), by proposing a new node status called vice- $\mathrm{CH}$, it presents the successor of $\mathrm{CH}$, when the $\mathrm{CH}$ exhaust its energy. In Multi Hop LEACH (M-LEACH), authors propose a new improvement approach which the multihop technique is used between $\mathrm{CHs,} \mathrm{to}$ transmit information to the Base station.

In this paper, two techniques are proposed in order to improve LEACH protocol in terms of network lifetime and energy efficiency. We suggest a new protocol named Location LEACH(LOC-LEACH), which organize nodes into 3 logical regions based on their location information, and a new cluster head election process is proposed by taking energy efficient as an important metric. Basically, the most important objective of this study is to extend network lifetime of WSNs and offer more stability for the network by minimizing energy dissipation. Simulation results confirm the performance of Our protocol. The remaining of the paper is organized as follows: Section 2 presents the comparison between cluster based and location based routing protocols in wsn. While section 3 describes our proposed protocol. In section 4, simulations results are discussed. Finally, Section 5 concludes our future works. 


\section{CLUSTER-BASED ROUTING PROTOCOLS}

Cluster-based routing protocols are structured of rounds. Each round is composed in four stages: Cluster head selection, cluster formation, intra-cluster communication andinter-cluster communication [11]. The network is organized intological groups which depend on network characteristics andapplications' requirementsIn the first stage, the Cluster Head $(\mathrm{CH})$ nodes are selected with a requirements and metrics defined by the routing protocol [1]. It is the local coordinator that aggregates and forwards data from its cluster members to base station. This is followed by the construction of clusters. In this second step, the Ordinary nodes choose their ideal $\mathrm{CH}$ by respecting the defined metrics to join it and form the cluster. This step is finalized once all nodes are assigned to a cluster.In intra-cluster communication step, the Ordinary nodes transmit data to their CHs. After collecting the data from their cluster members, the $\mathrm{CHs}$ perform data aggregation to omit the redundant data. In inter-cluster communication stage, the $\mathrm{CHs}$ transmit the aggregate data to the BS[11], [12]. Another node status is defined in the cluster called gateway nodes. It responsible to link between two clusters by connects one or more $\mathrm{CHs}$ and forms a predefined multihop intercluster communication route Each $\mathrm{CH}$ maintains in its routing table, information about all neighboringgateways, to choose the most optimized routing decision.Several advantages are provided by the cluster-based concept:

- Using the multihop routing concept allows to decrease the number of transmission routes, which decrease energy consumptionensuring the connectivity among the sensor nodes. [12].

- To reduce the network traffic toward the sink, Data aggregation concept is used, to eliminate data collision and redundant data [13].

Low energy adaptive clustering hierarchy (LEACH)[14]:LEACH is one of the most popular clustering protocols in WSN[2]. It is a distributed algorithm proposed by W. R. Heinzelman, A. P. Chandrakasan and H. Balakrishnan. Several protocols have relied on LEACH to present their concepts like TEEN, PEGASIS. The nodes in LEACH have autonomous decisions to become $\mathrm{CH}$ without any BS control[12], [15]. The concept used allows to select the $\mathrm{CHs}$ periodically and randomly[13], [16]. The main idea is to allow every node to become a $\mathrm{CH}$ at least once of $\mathrm{N} / \mathrm{K}$ a round, where is the number of nodes in the network and $\mathrm{K}$ is the desired number of clusters. The main objective is to minimize the energy consumed by the nodes, through distribute energy with in a balanced manner between nodes, in order the extend network lifetime. The algorithm is divided into two main phases:

Set-up phase:In this phase, the clusters are formed and the $\mathrm{CHs}$ are selected. To select $\mathrm{CHs}$, each node determines a random number between 0 and 1 . this number is compared with a threshold value T (i).T(i) is defined as follows:

$$
\mathrm{T}(\mathrm{n})=\left(\frac{\mathrm{P}}{1-\mathrm{P} \times\left(\mathrm{r} \times \bmod \left(\frac{1}{\mathrm{P}}\right)\right)}\right) \text { if } \mathrm{n} \in \text { " }^{\prime} "
$$

Where $\mathrm{r}$ is the number of the current period, $\mathrm{P}$ is the desired percentage of $\mathrm{CHs}$, and $\mathrm{G}$ is the set of nodes that have not been selected as $\mathrm{CH}$ during the last $1 / \mathrm{P}$ periods. Two cases are to be envisaged, the nodes can become $\mathrm{CH}$, if the random number is less than $\mathrm{T}$ (i) value; otherwise it becomes an ordinary node. After choosing the $\mathrm{CHs}$, the ordinary nodes join their cluster by choosing their cluster head following the received signal amplitude, in case of equality, the nodes choose the $\mathrm{CH}$ randomly.

Transmission phase: Once the $\mathrm{CHs}$ construct their clusters, each cluster head will create a TDMA schedule for its members. Each $\mathrm{CH}$ collects data from its nodes, fuses this data and transmits an aggregated packet to the base station, as shown in figure 1 .

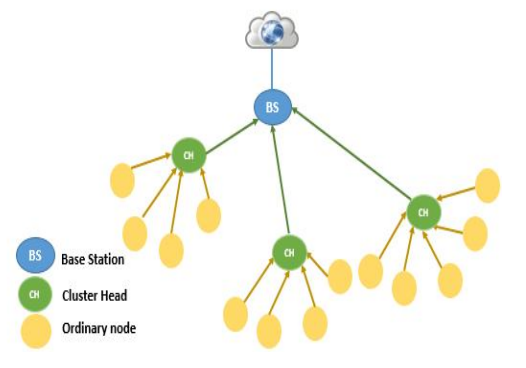

Figure 1: LEACH Protocol topology

In LEACH, localized coordination is used to allow robustness and scalability for network[16], andit reduces data global communication by using local compression. However, this protocol has some drawbacks, randomly $\mathrm{CH}$ election process does not take into account amount of $\mathrm{CH}$ energy and their location from the BS[15],single hop routing is used in intertransimission and intra transmission.

There are several authors proposed enhanced versions of leach in order to improve these drawbacks, such as, Centralized LEACH (LEACH-C)[17],this protocol has been proposed in order to solve some limitations of LEACH [12], [16]. LEACH-C proposes a new concept of cluster formation taking account the location and residual energy of each node [13], [17]. The BS receives the residual energy and location by using GPS of each node. Then, it determines the nodes to become $\mathrm{CHs}$ and the others nodes are signed to the $\mathrm{CHs}$ to form different clusters. A mean energy is defined to select nodes that can become a $\mathrm{CH}[16]$. In EnergyLEACH (E-LEACH) [18], authors improve LEACH by proposing to use the node's residual energy in the Cluster head election. Two-level LEACH (TL-LEACH) [19] is a LEACH enhanced version. In transmission phase, each $\mathrm{CH}$ collects data from nodes of its cluster. After that, instead of transferring the data directly to the BS, it uses one of the $\mathrm{CHs}$ that lies between the $\mathrm{CH}$ and the $\mathrm{BS}$ as a relay station. Multi Hop LEACH (M-LEACH)performs LEACH in terms of data transmission between $\mathrm{CHs}$ and $\mathrm{BS}$ [13]. Each $\mathrm{CH}$ collects its nodes data and transmits it to the nearest $\mathrm{CH}$. The protocol defines the optimal path between the BS and the $\mathrm{CH}$ using others $\mathrm{CHs}$. These $\mathrm{CHs}$ represent the relay to transmit data over through them. Vice-Leach protocol (VLEACH) [20] divides status nodes in each cluster in types, $\mathrm{CH}$, Ordinary nodes and the Vice $\mathrm{CH}$. This last Status it's the new concept proposed by V- LEACH. The Vice $\mathrm{CH}$ presents the successor of $\mathrm{CH}$, when the $\mathrm{CH}$ exhaust its energy. It selected from basis the distance with the $\mathrm{CH}$ and its residual energy. V-LEACH protocol come in order to 
avoid the executing of the operation of $\mathrm{CH}$ election in each round, for minimizing the energy consumption and prolonging network life time.

\section{LOCATION-BASED PROTOCOLS FOR WSNS}

In location-based routing, the node finds its next hop using the location information. This type of protocols allows to have effectiveresults in terms of routing data packet[8], [9]. In order to evaluate the energy consumption, the location based routing protocols should compute the distance among two specific nodes, based on the strength of the incoming signal.The concept of using location of nodes, allows networks to choose the best route with minimal energy consumption, for providing the higher efficiency and scalability across the network.Location based routing is characterized by these 3 main concepts:Each node must know its own location information by GPS or by any other methods(anchor based or anchor free, centralized or distributed, GPS based or GPS free), each node must be aware of the location of its neighbouring nodes, (one hop away from it) the source node must be aware of the location of destination node[8], [9].

Geographic adaptive fidelity (GAF) [21] :This protocol is mainly concerned with energy consumption, by using the concept turn on/off the nodes in the network[9].In order to conserve energy and also keep a constant level of fidelity,GAF divides the sensor area into virtual grid. The position of each node defines in which area it will be affected. Nodes in the same grid are considered equivalent in term of cost of packet routing[9]. The location information is provided by GPS or other location systems. GAF can be divided into 3 phases :

- Discovery : Each node discovers the other nodes of its same grid by exchanging messages.

- Active: In order to conserve the energy, only active nodes can indicate about their participating in routing operation.

- Sleep : Formaintaining routing fidelity, eachnonactive nodes go to sleep and its radio is turned off. When the leaving time of the active nodes expire, the inactive nodes must wake up and become active

Reception phase andCoordination of power saving with routing(SPAN)[22]: SPAN isa distributed, randomized algorithm where the concept of energy conservation is used. One node from all nodes in the network is selected as a coordinator in order to participate in routing. The coordinator stays awake, to ensure the routing tasks, while the other nodes in the network turn off their radios for conserving their energy.

In SPAN, the nodes are divided into 2 states: Coordinator and no-coordinators, the coordinator is elected by considering two important metrics, the energy level of the node and an estimate of how many of its neighbors will benefit from it being awake. The role of coordinator is to alternate between all nodes, to ensure load balancing in the network.SPAN is a routing protocol primarily proposed for MANETs, but it'salso used forWSNs. The main objective is to reduce energy consumption of the network.
Geographic and energy-aware routing (GEAR) [23] : GEAR is an energy efficient protocol where the routing messages are diffused to appropriate regions. To identify the position of the nodes, a specific location hardware such as GPS is used. GEAR assumes that each node knows, on the one hand its remaining energy level, its current location and the other hand its neighbours location, and their energy level.4In GEAR nodes are considered static, they don't need a location database. The link is assumed to be bi-directional. Two types of cost parameters are defined:

-Estimated cost: Itrepresents the combination of distance to destination and a residual energy.

-Learned cost: It is an enhancement of the approximated cost that takes care of the routing holes in the WSN. A hole in the routing path means that a node is not having any closer neighbour to the target region than itself. Theprotocol can be divided in 2 phases:

Phase 1 Routing Data to destination region: when the data is received by the node, it must check if a neighbour node is closer to the destination region than itself. If there is more than one, the next hop is the nearest neighbour to the destination region. If all neighbouring nodes are further away,in this case there is a hole and the solution is that one of the neighbors is chosen to route the data based on the learning cost function.

Phase 2 Transmitting the data within the region: To diffuse the data in the region, 2 methods can be used, either recursive geographic transmitting or restricted flooding. Restricted flooding technique, can be used in the case of a dense network. In case of high-density network, recursive geographic flooding is more energy efficient than restricted flooding and the region is divided into four sub regions and four copies of the packet are created.This phase continues until the region with only one node are left. Table 1 shows the various modifications of GEAR Protocol.

Table 1: The various modifications of GEAR Protocol

\begin{tabular}{|c|c|c|}
\hline ProtocolName & bjective $^{\mathrm{O}}$ & Advantages \\
\hline $\begin{array}{l}\text { CentralizedClusteringGeograph } \\
\text { icEnergy awareRouting } \\
\text { (GEAR-CC) }\end{array}$ & $\begin{array}{l}\text { load } \\
\text { balancing } \\
\text { among all } \\
\text { nodes in } \\
\text { the } \\
\text { network } \\
\text { in terms } \\
\text { of energy } \\
\text { consumpt } \\
\text { ion and } \\
\text { finding } \\
\text { the best } \\
\text { routing } \\
\text { path }\end{array}$ & $\begin{array}{l}\text { Best } \\
\text { energyefficie } \\
\text { ncy } \\
\text { andextend } \\
\text { network } \\
\text { lifetime }\end{array}$ \\
\hline $\begin{array}{l}\text { QoSGeographicEnergy } \\
\text { awarerouting }\end{array}$ & $\begin{array}{l}\text { Take into } \\
\text { account } \\
\text { QoS } \\
\text { routing } \\
\text { issue } \\
\text { (bandwidt } \\
\mathrm{h} \text { and } \\
\text { delay) }\end{array}$ & $\begin{array}{l}\text { Improved } \\
\text { packetdelive } \\
\text { ry Ratio }\end{array}$ \\
\hline $\begin{array}{l}\text { Energy AwareGeographic } \\
\text { RoutingAlgorithm (EGR) }\end{array}$ & $\begin{array}{l}\text { Load } \\
\text { balancing }\end{array}$ & $\begin{array}{l}\text { Increased } \\
\text { Networklifet }\end{array}$ \\
\hline
\end{tabular}




\begin{tabular}{|c|c|c|}
\hline & $\begin{array}{l}\text { among all } \\
\text { nodes in } \\
\text { the } \\
\text { network } \\
\text { in terms } \\
\text { of energy } \\
\text { consumpt } \\
\text { ion } \\
\text {-Prolong } \\
\text { network } \\
\text { lifetime }\end{array}$ & $\begin{array}{l}\text { ime and } \\
\text { datadelivery } \\
\text { Rate }\end{array}$ \\
\hline $\begin{array}{l}\text { Multihop-Gateway Energy } \\
\text { AwareRouting Protocol (M- } \\
\text { GEAR) [ 24] }\end{array}$ & $\begin{array}{l}\text { Divide } \\
\text { the sensor } \\
\text { nodes } \\
\text { into four } \\
\text { logical } \\
\text { regions } \\
\text { on the } \\
\text { basis of } \\
\text { their } \\
\text { location } \\
\text { in the } \\
\text { sensing } \\
\text { field } \\
\text { InstallBas } \\
\text { e Station } \\
\text { (BS) out } \\
\text { of the } \\
\text { sensing } \\
\text { area and a } \\
\text { gateway } \\
\text { node at } \\
\text { the centre } \\
\text { of the } \\
\text { sensing } \\
\text { area. [13] }\end{array}$ & $\begin{array}{l}\text { To } \\
\text { minimizeene } \\
\text { rgy } \\
\text { consumption } \\
\text { of sensor } \\
\text { network is } \\
\text { presented } \\
\text { and the } \\
\text { network is } \\
\text { divide into } \\
\text { logical } \\
\text { regions }\end{array}$ \\
\hline
\end{tabular}

\section{PROPOSED ALGORITHM}

Balancing energy between nodes represents a good approach to conserve energy and maximize network lifetime in WSNs. To achieve these objectives, LEACH protocol takes to all nodes the same opportunity to become $\mathrm{CH}$. This method does not take into account the amount of energy of the $\mathrm{CH}$, which performs additional tasks compared to ordinary nodes. Distribute network nodes into 3 logical regions, along with efficient cluster head selection process will be presented in this research. Our work is based on LEACH protocol, we introduce these two techniques to increase network performance, including network stability, throughput and network lifetime.

In this section we present our proposed protocol. We discuss their principal characteristics, in terms of energy efficient and network lifetime. The main idea of this protocol named Location-based LEACH (LOC-LEACH) is to propose an improvement of LEACH protocol. LOC-LEACH is divided in 4 phases:

\subsection{Initialisation phase}

In this step, nodes are distributed randomly in sensor area. This phase starts with a message diffused by the base station to all nodes in the network. In response, each sensor node sends its location to the BS. After that, the distance between the BS and each node will be calculated by the BS. Each sensor node has its data table, which contains the following information: distinctive node, residual energy of node, location of node and its distance to the BS.

\subsection{Setup phase}

The energy consumption of a node depends of its location and distance from the $\mathrm{CH}$ or base station. The node near the base station consumes less energy than a node at the end of the network. For this reason, a good strategy according to sensor node location is necessary to balance energy consumption. The solution is to group nodes according to their location. Sensor nodes in the same region will form the same cluster and will have the same management, to achieve high energy efficiency and improve network scalability. This phase consists of organizing nodes in regions according to their location in the network. Our network will be divided into 3 different logical regions. The main idea of this distribution, is to allow nodes close to the base station to be in autonomous communication, due to the small distance that separates them from the BS. These sensor nodes do not need to waste their energy in clustering operations such as: $\mathrm{CH}$ selection process, data aggregation. Each node whose location from the base station is less than or equal to the threshold Td, will be assigned to the region-one. This region uses direct communication and each node transmits its data directly to BS. All other nodes are divided into two equal half regions sensor nodes. In these regions, nodes are organized into small clusters, and cluster-based routing is adapted. Figure 2 shows, topology of our proposed protocol

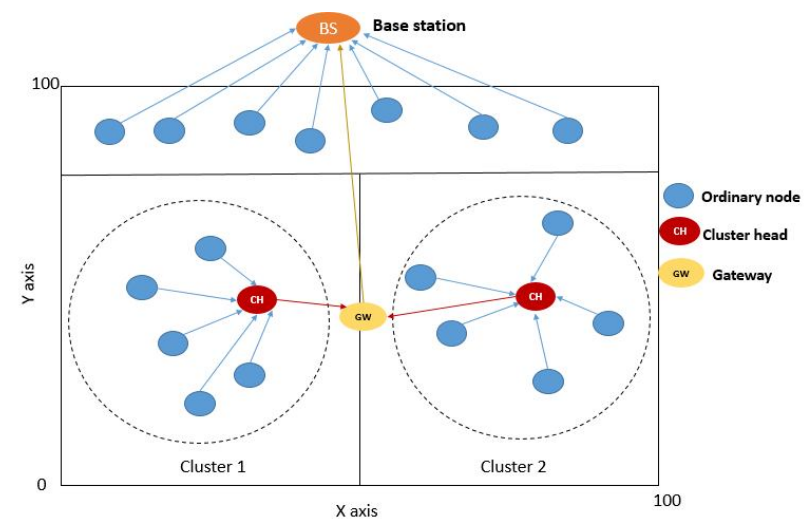

Figure 2: LOC-LEACH: Protocol topology

\subsection{Cluster head election}

The $\mathrm{CH}$ election operation is carried out in the clustered regions. The main objective is to modify the $\mathrm{CH}$ election process proposed by LEACH. In LEACH protocol, The $\mathrm{CH}$ is changed at every round and once a cluster head is elected, it will not get another possibility to become $\mathrm{CH}$ for next $1 / \mathrm{p}$ rounds. For each round, $\mathrm{CHs}$ are changed and whole cluster formation process is executed. Thus, the extra energy loss and the degradation of the network life time are caused, due to the premature loss of some sensor nodes. To solve this problem, a threshold level energy Tc is adopted. The current $\mathrm{CH}$ will be changed once its energy level is less than the defined threshold Tc. The cluster formation process is executed only in region concerned, independent of other region. The next $\mathrm{CH}$ is elected randomly provided that its energy is higher than the threshold Tc. If all nodes of the 
cluster have an energy lower than the Threshold, the next $\mathrm{CH}$ is elected according to LEACH cluster formation. The proposed concept, allows a novel energy balancing applying into clusters, that balance the energy consumption of the sensor nodes and prolong network lifetime. The $\mathrm{CH}$ election algorithm is shown in figure 3 below.

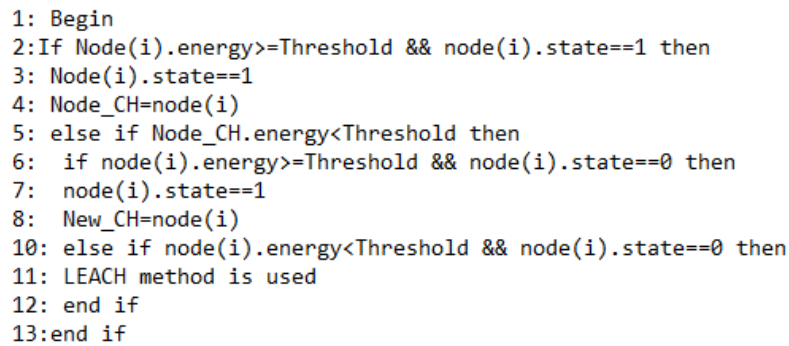

Figure 3: $\mathrm{CH}$ election process in LOC-LEACH

\subsection{Transmission}

Once the clusters of both regions are formed, each $\mathrm{CH}$ will create a TDMA schedule for its members. Then it collects their data, merges them and sends an aggregate packet to the gateway. Gateway node gathers data from $\mathrm{CHs}$, fuses and transmits them to BS. It issues a TDMA schedule for the both $\mathrm{CHs}$, then each $\mathrm{CH}$ informs its cluster members by its own TDMA schedule. Nodes in region-one send their data directly to BS, direct communication is used due to the short distance to the BS. The proposed concept is shown in figure 4 below.

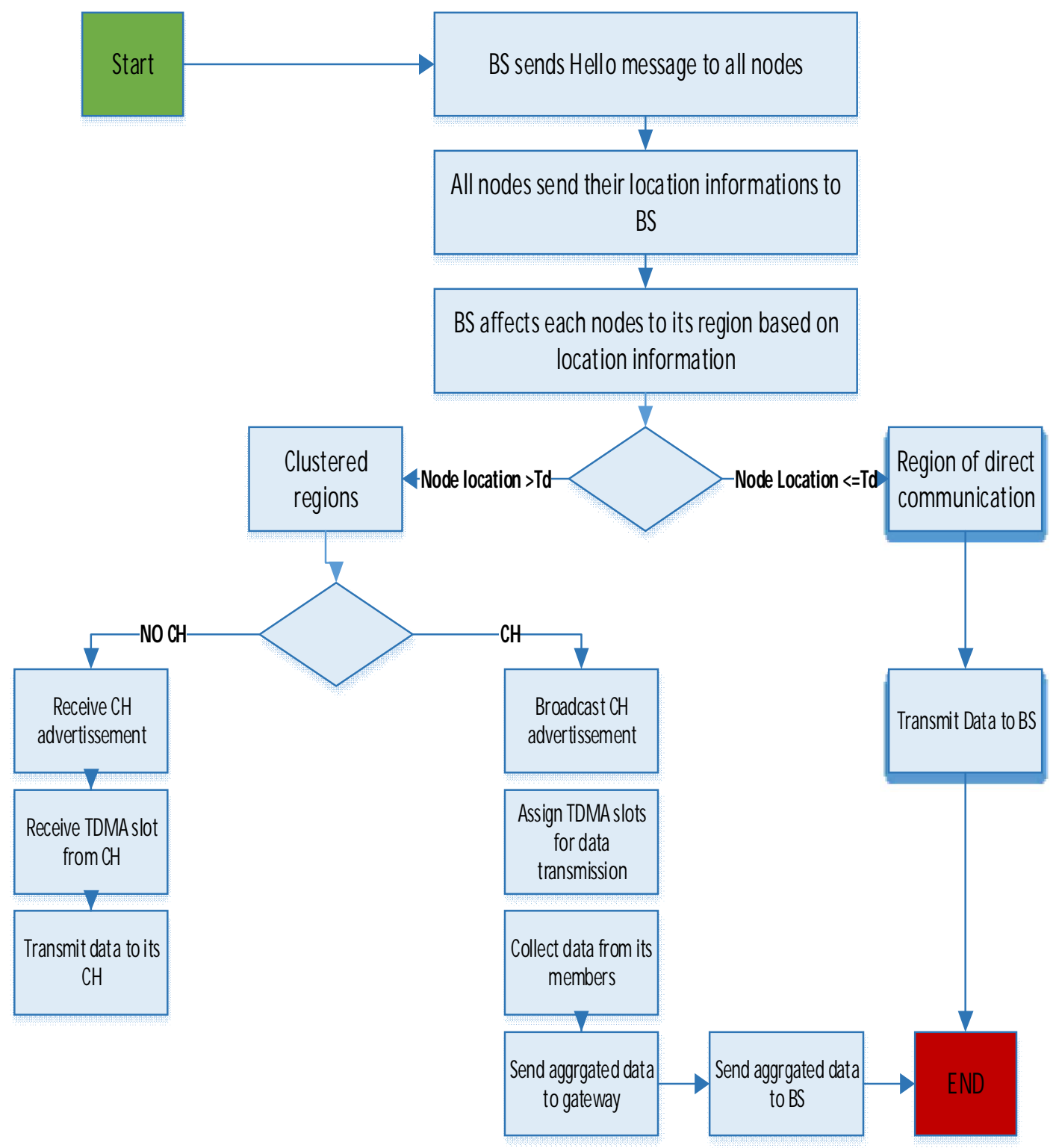

Figure 4: The flowchart of LOC-LEACH 


\section{RESULTS AND ANALYSIS}

In this section we discuss simulations results of LOCLEACH using Matlab simulator, and compare them with LEACH protocol. In our simulation, we consider:

- A wireless sensor network with 100 nodes distributed randomly in $100 \mathrm{~m} \times 100 \mathrm{~m}$ field,

- The BS is situated distant from the sensing field, and it is stationary after deployment

- A gateway node is located at the center of the network, and it is stationary after deployment.

- Sensor nodes are homogeneous and with same characteristics in terms of computing energy, and sensing.

Parameters for our simulation are given in the table 2 below.

Table 2: Simulation Parameters

\begin{tabular}{|c|c|}
\hline Parameter & Value \\
\hline Network size & $100 \mathrm{~m} * 100 \mathrm{~m}$ \\
\hline Initial Energy & $0.5 \mathrm{~J}$ \\
\hline Base station location & 50,120 \\
\hline $\begin{array}{c}\text { Data Aggregation Energy } \\
\text { cost }\end{array}$ & $5 \mathrm{pJ} / \mathrm{bit}$ \\
\hline Number of nodes & 100 \\
\hline Packet size & $4000 \mathrm{bit}$ \\
\hline transmission energyEelec & $5 \mathrm{~nJ} / \mathrm{bit}$ \\
\hline Reception energy Efs & $10 \mathrm{pJ} / \mathrm{bit} / \mathrm{m} 2$ \\
\hline Transmit amplifier (Eamp) & $0.0013 \mathrm{pJ} / \mathrm{bit} / \mathrm{m} 4$ \\
\hline
\end{tabular}

\subsection{Network stability}

Stability period represents the period when the network keeps its initial topology, before the death of the first node. LOC-LEACH extends stable period due to its repartition of nodes into logical region and efficient $\mathrm{CH}$ replacement process. Simulated results depicted in figure 5 and figure 6 , represent network lifetime by showing comparison of number of dead nodes throughout the simulation process Providing total network stability with its initial state is very important for some deployed networks [16]. Whose main objective is to have the information while keeping the initial state of the network, before the loss of the first network node.

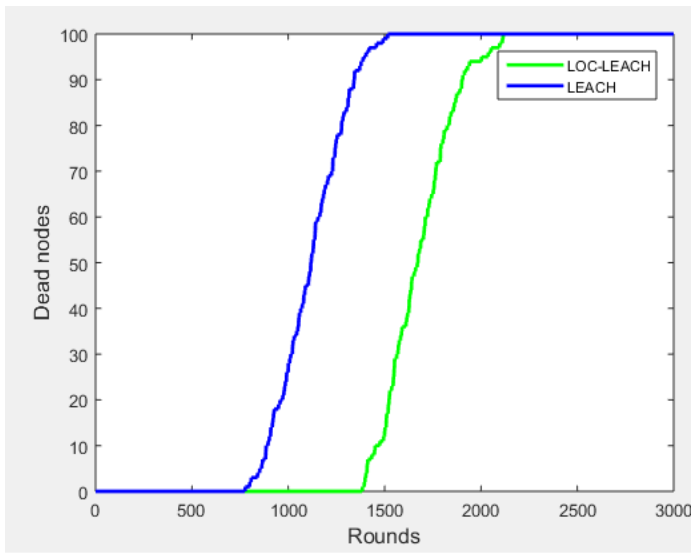

Figure 5: Dead Nodes Comparison

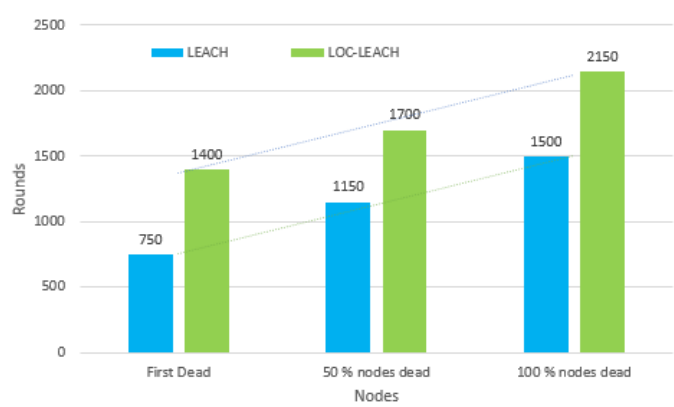

Figure 6. Dead Nodes Repartition

\subsection{Network lifetime}

Network Lifetime is defined as to be the time period during which the network can perform its defined objective. It represents an important metric to evaluation energy consumption and $\mathrm{CH}$ election process. Figure7 shows that our proposed LOC-LEACH protocol allows better performance of alive nodes throughout the simulation as compare to $\mathrm{LEACH}$, this is because the energy consumption is uniformly distributed among all nodes. LOC-LEACH divides network into logical regions and avoids unnecessary execution of $\mathrm{CH}$ election process into clustered region. Our proposed techniques balance energy consumption among all nodes. However, in LEACH, randomly process of CHelection does not optimize the conservation of energy among nodes and reduces significantly network lifetime [13].

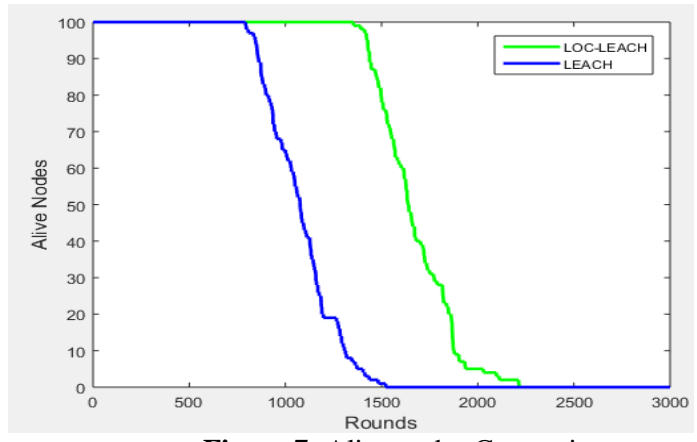

Figure 7: Alive nodes Comparison

\subsection{Throughput}

Throughput means the average number of packets received at base station per round. Throughput of the network is of the biggest factor of network performance. In figure 8, the throughput of the network can be evaluated. Our proposed LOC-LEACH mechanism adopts direction communication in region nearest to $\mathrm{BS}$, and transmission using the gateway in clustered region. LOC-LEACH gives better packet delivery rate at destination as compared to LEACH 


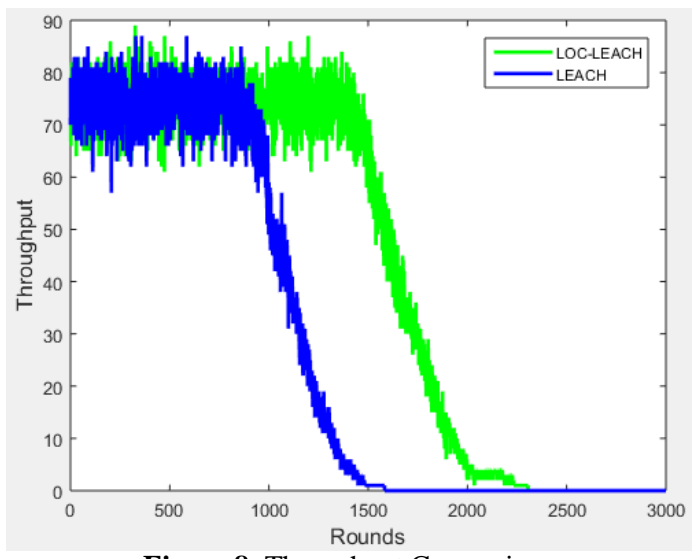

Figure 8: Throughput Comparison

\subsection{Energy consumption}

LOC-LEACH yields minimum energy consumption than LEACH. Figure9 clearly depicts that our protocol outperforms LEACH routing protocol in terms of energy consumption per round. The enhanced strategy for selection $\mathrm{CH}$, as well as the distribution of the network in 3 regions, allow to optimize the energy consumption of the network in a remarkable manner.

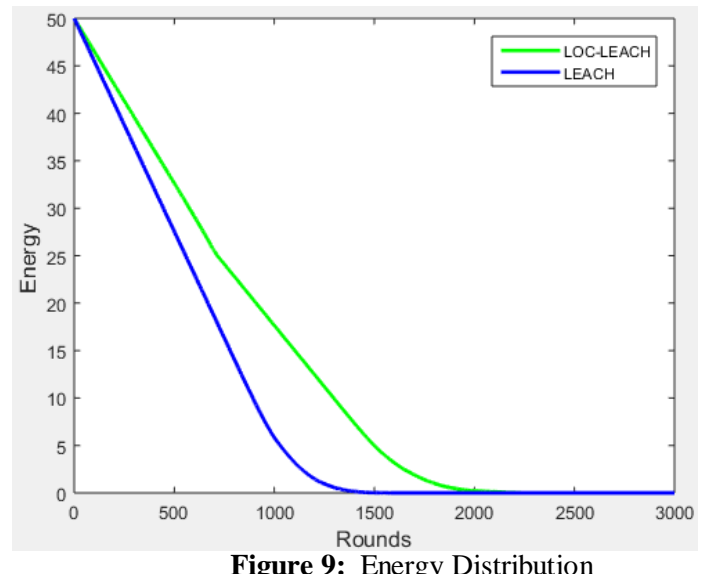

\section{CONCLUSION AND FUTURE WORKS}

Energy balancing among sensor nodes is of key important factor in WSN for prolonging network lifetime. Protocol design should be capable to offer a best distribution in terms of nodes location and energy consumption. In this paper, two efficient techniques have proposed, in order to enhance LEACH protocol. We divide the network into three logical regions. The first region that consists of the nodes close to the base station, direct communication strategy is used. The two others are structured into cluster. In addition, a new $\mathrm{CH}$ selection process is implemented to allow a uniform distribution of energy. The main objective of this work is to propose an enhanced version of LEACH protocol, in order to extend WSN lifetime time and efficiently balance energy consumption between nodes. The experiments show that our algorithm LOC-LEACH is better than LEACH in terms of network stability, network lifetime, energy consumed and throughput.
As part of our future work, we are going to investigate how to define with a detailed manner the both threshold. The threshold responsible for defining the direct transmission region and the threshold that allows to launch the operation of $\mathrm{CH}$ selection. To further improve the performance of our routing algorithm.

\section{REFERENCES}

1. S. V. Manikanthan, T. Padmapriya," An Efficient Cluster Head Selection and Routing in Mobile WSN", International Journal of Interactive Mobile Technologies, Vol 13, No 102019 https://doi.org/10.3991/ijim.v13i10.11303

2. Vrinda Gupta, Rajoo Pandey, " Modified LEACH-DT Algorithm with Hierarchical Extension for Wireless Sensor Networks', I. J. Computer Network and Information Security, 2, 32-40, 2016

3. Mohsen Kadi, IYAD Alkhayat (2015), "Effect of location errors on location based routing protocols in wireless sensor networks," Egyptian Informatics journal (2015) 16,113-119 https://doi.org/10.1016/j.eij.2015.02.001

4. Krati Rastogi , Kaushik Ghosh ;" The effect of multiple sink on the lifetime of WSN fordifferent grid geometry,": International Journal of Advanced Trends in Computer Science and Engineering, Volume 6, No.2, March - April 2017

5. Mohsen Nasri, Abdelhamid Helali, Halim Sghaier, Hassen Maaref, " Efficient JPEG 2000 Image Compression Scheme for Multihop Wireless Networks ", TELKOMNIKA, Vol.9, No.2, August 2011

6. Mohammed Reda El Ouadi, Abderrahim Hasbi; (2018); "HEGASIS: Hybrid, Energy Efficient Gathering in Sensor Information Systems;" International Journal of Advances in Scientific Research and Engineering (ijasre); Volume 4, https://doi.org/10.31695/IJASRE.2018.32978

7. Mohammad Hossein Anisi et al, " Energy harvesting and battery power based routing in wireless sensor networks", Mobile Networks and Applications, volume 23, pages456-468(2018)

8. Mohammed Réda El Ouadi, Abderrahim Hasbi, ", Performance evaluation of PEGASIS protocol for WSN using Matlab," International Journal of Advanced Studies in Computers, Science and Engineering; Gothenburg Vol. 8, N 11, (2019): 10-16.

9. Jitender Grover, Shikha , Mohit Sharma, 'Location Based Protocols in Wireless Sensor Network - A Review', Fifth International Conference on Computing, Communications and Networking Technologies (ICCCNT) 2014 https://doi.org/10.1109/ICCCNT.2014.6962990

10. Abdulmughni Hamzah et al,' Energy-Efficient FuzzyLogic-Based Clustering Technique for Hierarchical Routing Protocols in Wireless Sensor Networks', Sensors, 2019, 19, 561

11. Bahram Moradi Nezhad, Mojtaba Alizadeh, Touraj Khodadadi," Extending the Network Lifetime by Distributed Selection of Cluster Head in 
Homogeneous Wireless Sensor Networks', International Journal of Advanced Trends in Computer Science and Engineering, Volume 9, No.3, May - June 2020 https://doi.org/10.30534/ijatcse/2020/94932020

12. Trong-The Nguyen, Jeng-Shyang Pan, and Thi-Kien Dao," A Compact Bat Algorithm for Unequal Clustering in Wireless Sensor Networks ", Applied. Science., 9(10), 2019.

13. Heen-a Dhawan, Sandeep Waraich, "A Comparative Study on LEACH Routing Protocol and its Variants in Wireless Sensor Networks: A Survey ", International Journal of Computer Applications, Volume 95- No.8, June 2014 https://doi.org/10.5120/16614-6454

14. W.R. Heinzelman, A. Chandrakasan, and H. Balakrishnan, "Energy-Efficient Communication Protocol for Wireless Micro Sensor Networks," Proceedings of the 33rd Annual Hawaii International Conference on Proceedings of the 33rd Annual Hawaii International Conference on Page: 10, 2002

15. Ghassan Samara , Munir Al-okour ,' Optimal Number of Cluster Heads in Wireless Sensors Networks Based on LEACH', Optimal Number of Cluster Heads in Wireless Sensors Networks Based on LEACH, Volume 9, No.1, January - February 2020

16. John Anzola et al, "A Clustering WSN Routing Protocol Based on k-d Tree Algorithm", sensors, 2018

17. Wendi B. Heinzelman," An Application-Specific Protocol Architecture for Wireless Microsensor Networks," IEEE Transactions on Wireless Communications, vol. 1, no. 4, October 2002. https://doi.org/10.1109/TWC.2002.804190

18. Fan Xiangning, Song Yulin, 'Improvement on LEACH protocol of Wireless Sensor Network', International Conference on Sensor Technologies and Applications, 2007

19. V. Loscrì, G. Morabito, S. Marano ;(2005); A TwoLevels Hierarchy for Low-Energy Adaptive Clustering Hierarchy (TL-LEACH)," IEEE 62nd Vehicular Technology Conference, 2005.

20. M. Bani Yassein, A. Al-zou'bi, Y. Khamayseh, W. Mardini;','Improvement on LEACH Protocol of Wireless Sensor Network (VLEACH)'; 2007 International Conference on Sensor Technologies and Applications (SENSORCOMM 2007)

21. Xu, Y., Heidemann, J. and Estrin," GeographyInformed Energy Conservation for Ad Hoc Routing", Proceedings of the 7th Annual International Conference on Mobile Computing and Networking, Rome, Italy, 16-21 July 2001, 70-84. https://doi.org/10.1145/381677.381685

22. Chen, B., Jamieson, K., Balakrishnan, H. and Morris,"Span: An Energy- Efficient Coordination Algorithm for Topology Maintenance in Ad Hoc Wireless Networks," Wireless Networks, 2002, 481494.

https://doi.org/10.1023/A:1016542229220

23. Yan $\mathrm{Yu}$, Ramesh Govindan, Deborah Estrin," Geographical and Energy Aware Routing: A
Recursive Data Dissemination Protocol for Wireless Sensor Networks," UCLA Computer Science Department Technical , 2001

24. Q. Nadeem, M. B. Rasheed1, N. Javaid, Z. A. Khan, Y. Maqsood, A. Din;(2013),'M-GEAR: Gateway-Based Energy-Aware Multi-Hop Routing Protocol for WSNs; "Eighth International Conference on Broadband and Wireless Computing, Communication and Applications, 2013

https://doi.org/10.1109/BWCCA.2013.35 